\title{
Supercritical Carbon Dioxide Extraction of Indian Orange Peel Oil and Hydro Distillation Comparison on Their Compositions
}

\author{
Omprakash H. Nautiyal", Krishan Kant Tiwari \\ Department of Chemical Engineering, Institute of Chemical Technology, NM Parikh Marg, Matunga (E), Mumbai, 400019, India
}

\begin{abstract}
Orange peel oil being very useful in foods, flavor, and pharmaceutical industry consumed worldwide. An attempt was made to extract the oil using $\mathrm{SC}-\mathrm{CO}_{2}$ to study the quality, quantity and compositions of the oil. Pressures ranging from 8-15 $\mathrm{MPa}$ with temperatures ranging from $28-60^{\circ} \mathrm{C}$ were employed. Quality of the oil was analyzed by GC and Capillary GC. Supercritical carbon dioxide was found to extract the oil containing all the low volatile fractions and oil obtained was light pale yellow in color. Shelf life of the oil was found much better than that extracted with conventional techniques. Various pre-treatments were exercised to prolong the good life of peels to study the impact on their physical properties and quality along with the yields. Alkaline treatment of the orange peels reveals some important observations in the extractions of constituents.
\end{abstract}

Keywords $\mathrm{SC}-\mathrm{CO}_{2}$, Orange peels, Pre treatments, Hydro distillation, Quality, Yield

\section{Introduction}

Our aim of the research was to develop the feasible process of extracting Orange peel oil and to best manage the huge waste of orange peels. Different range of pressure and temperature was studied along with batch time variation. Flow rate of supercritical carbon dioxide was not of great importance as the higher flow rates did not contributed in the yield enhancement.

Hence the study was investigated with the flow rate, $5 \mathrm{~kg}$ $\mathrm{h}^{-1}$ and resulted in recovering the Orange oil with the best yield and good flavor value. Researchers conducted by various authors using $\mathrm{SC}-\mathrm{CO}_{2}$ were found to show the interesting results but our study has obtained the best yield of the oil than that reported. [1-5]

Supercritical fluid (SCF) extraction is an extraction process utilizing a fluid as an extract -ant at temperatures and pressures exceeding its critical temperature and pressure. Within the past three decades numerous industrial and academic research and development laboratories have investigated the underlying fundamentals and process applications of supercritical fluid (SCF) as solvents. It is possible to separate a multi component mixture when a supercritical fluid is used as an extractive solvent by capitalizing on both the differences in component volatilities

Corresponding author:

opnautiyalus@yahoo.com (Omprakash H Nautiyal)

Published online at http://journal.sapub.org/scit

Copyright (C) 2012 Scientific \& Academic Publishing. All Rights Reserved (i.e., salient features of distillation) and the differences in the specific interaction between the mixture components and the SCF solvent (i.e., the salient features of solvent extraction). The application of SCF solvents is based on the experimental observations that many gases exhibit enhanced solvating power when compressed to conditions above the critical point.

G. Della Porta1996 have studied desorption of bigarade peel oil from a polar adsorbent was performed by supercritical $\mathrm{CO}_{2}$ to improve the oil quality by selectively eliminating hydrocarbon terpenes and coumarins. The oil fractions obtained at $40^{\circ} \mathrm{C}$, at pressures between 7.7 and $12 \mathrm{MPa}$, and at different desorption times were analyzed by GC-MS. Three fractions were characterized: terpenic fraction, deterpenated fraction, and residue. The content of oxygenated compounds in the deterpenated fraction was 6.6 times higher than in the crude oil. Coumarins, psoralens, polymethoxy flavones, and waxes contained in the starting material were recovered and identified in the residue fraction.

Gonzalo A. N. et al. 2010 studied the solubility in supercritical carbon dioxide $\left(\mathrm{CO}_{2}\right)$ of farnesol using a static-analytic method (a high-pressure static equilibrium cell coupled to an HPLC). The differences in solubility between farnesol, naringenin, and other sesquisterpenes or flavonoids reported in the literature were partially explained by differences in molecular weight and polarity between solutes. They correlated experimental data as a function of the system temperature and pressure and the density of the solvent using a literature model that also showed the auto 
consistency of the data for $\mathrm{CO}_{2}$ densities above $412 \mathrm{~kg} \cdot \mathrm{m}-3$ for naringenin. [5-8]

B. Mira, M. Belasco, S. Subirats and A. Berna 1996 studied the supercritical fluid extraction of orange essential using dehydrated orange peel $\left(0.0538 \mathrm{~kg} \mathrm{H}_{2} \mathrm{O} \mathrm{kg}^{-1} \mathrm{dm}\right)$ from nave line cultivars as raw material and $\mathrm{CO}_{2}$ as solvent. The effect of operation conditions was analyzed in a series of experiments at 313 and $323 \mathrm{~K}$ and pressures between 1 and $25 \mathrm{MPa}$. Furthermore, the effect of $\mathrm{CO}_{2}$ flow rate and particle size of orange peel was studied in the range of 0.5 to $3.5 \mathrm{~kg} \mathrm{~h}^{-1}$ and 0.1 to $10 \mathrm{~mm}$. The subcritical $\mathrm{CO}_{2}$ dissolves hardly any essential oils, however, on reaching the critical point, the amount of essential oils dissolved increased with pressure, within the range of pressures considered in this study. Increasing solvent mass flow decreased the extraction efficiency while increasing particle size of orange peel decreased the extraction rate. For a rapid extraction, particle sizes lower than $2 \mathrm{~mm}$ and solvent mass flows lower than 2.5 $\mathrm{kg} \mathrm{h}^{-1}$ are adequate. A model based on the assumption of plug flow of a supercritical solvent through a fixed bed of milled material was applied to analyze the experimental results. The collected extracts were orange in color due to the carotenoid and flavonoid content. During the process, water was extracted in the final stage of the extraction. [9-11]

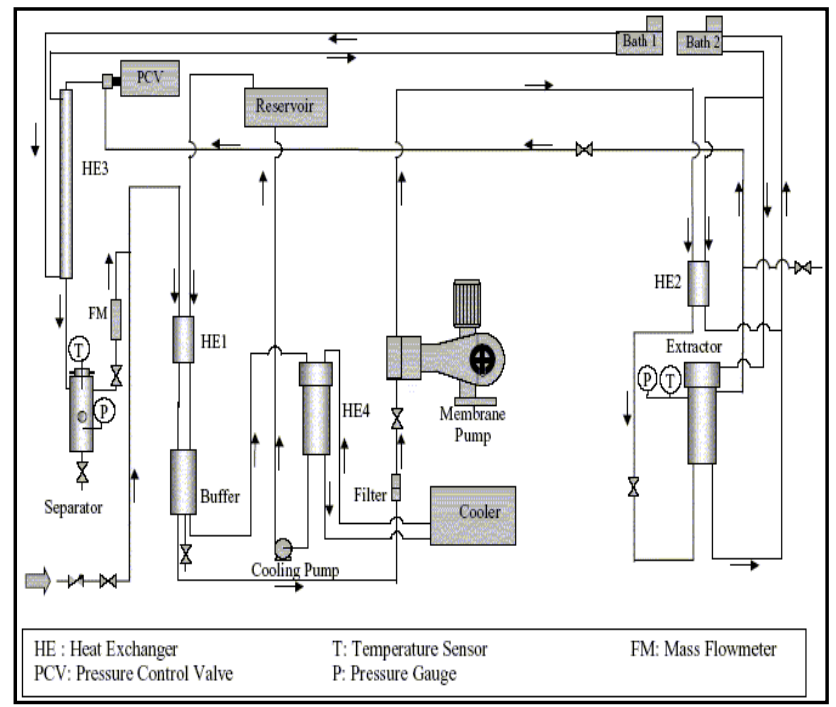

Figure 1. $\mathrm{SC}-\mathrm{CO}_{2}$ Pilot Plant schematic flow

\section{Materials and Methods}

\section{1. $\mathrm{SC}-\mathrm{CO}_{2}$ Extraction}

Carbon dioxide gas (99.9\%) was purchased from Indian Oxygen Limited. Orange peels were collected freshly from fruit merchant, local area of Matunga, Mumbai suburbs. The standards orange oil constituents were purchased from Sigma-Aldrich Co. (St. Louis, $\mathrm{MO}$ ). The $\mathrm{SC}-\mathrm{CO}_{2}$ pilot plant (Figure 1), with extractor and separator capacities of $1 \mathrm{~L}$ each, was imported from UHDE GmbH (Dortmund, Germany).

The $\mathrm{SC}-\mathrm{CO}_{2}$ pilot plant was procured with a grant from DST (Government of India).
Orange peels were collected from the fruit processing merchant procured from the Nagpur region of India and covers huge area for cultivation of Oranges. [1-5]

This region is a quality Orange producer and exporter of India. Peels as mentioned in this study were set for various pre treatments for evaluating the extraction processes such as SCF and conventional technology. Moisture content of the peels was determined using Clevenger apparatus and Karl-Fischer method. Research revealed the better results as those reported in the literatures. SFE was utilized by varying the pressures and temperatures to study the effect on yield and quality of orange oil. Comparative studies using convention technology did have some disadvantages on the yield and quality of oil. Physical properties were determined to find to approve the conformation of the extracted oil. Thus the physical properties determined were found to conform to the values obtained. [12-17]

Orange peels were grounded with the mild rpm so as to expose the oil sacs and the pulpy mass weighing $500 \mathrm{~g}$ was charged into the extractor and was closed. In the mean time the $\mathrm{CO}_{2}$ gas was allowed to bring in the supercritical fluid conditions by circulating it in the pre heat exchanger and the process was allowed for half an hour to forty five minutes. Thermostat was set as such to attain the experimental temperatures each time. Triplicate runs were conducted to validate the accuracy of the process. For the set batch time the separator was depressurize for recovery of the oil to assess the extraction. Extracted oil was analyzed by $\mathrm{GC}$ for its extracted constituents. The flow rate of the $\mathrm{SC}-\mathrm{CO}_{2}$ was changed from $5 \mathrm{~kg} \mathrm{~h}^{-1}$ to $20 \mathrm{~kg} \mathrm{~h}^{-1}$ to study the effect of the flow rate on extraction using performance curve. [18-19]

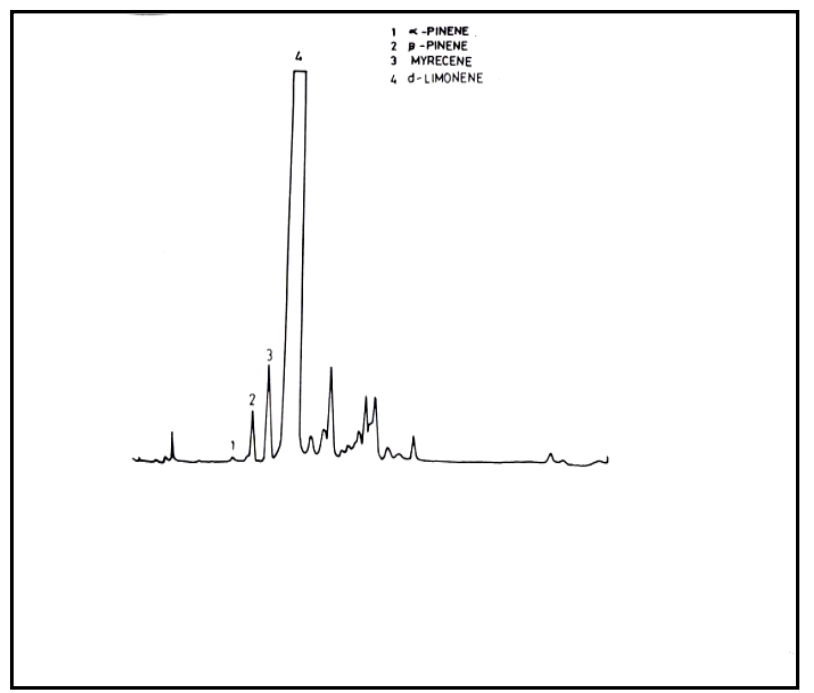

Figure 2. Orange peel oil analyses by gas chromatography

\subsection{Analysis of Orange Oil}

Analysis of Orange oil (figure 2) was done by using gas chromatography (Perkin-Elmer 8500), column specification and temperature programme are described as follows: column SE30 (10\%) on chromosorb W, column material S.S, column length 4 meter, internal diameter $1 / 8$ inch, injector temperature $300^{\circ} \mathrm{C}$, FID temperature $300^{\circ} \mathrm{C}$, 
flow rate of $\mathrm{N}_{2} 30 \mathrm{ml} /$ minute and temperature programming $100-250^{\circ} \mathrm{C}$ with $5^{\circ} \mathrm{C} /$ minute rise of temperature, final hold time 5 minute. [20-21]

\section{Results and Discussion}

\subsection{Effect of Pressure on the Extraction of Orange Oil}

In this part of study pressure was varied in between $8-25 \mathrm{MPa}$, at $55^{\circ} \mathrm{C}, 5 \mathrm{~kg} \mathrm{~h}^{-1}$ flow rate of $\mathrm{SC}-\mathrm{CO}_{2}$ and 2 hour batch extraction time. These data are presented in table 3 . With an increase in pressure at constant temperature the yield of the oil was found to increase till 150 bars. Above 150 bars decrease in the degree of extraction was noticed specifically at 20 and $25 \mathrm{MPa}$. Value addition components get extracted in the pressures range of 8-15 MPa. This pressure (table 1) onwards no increase in the yield of the oil was found. Anomalous behavior [18-19] of decrease in yield at high pressures at $55^{\circ} \mathrm{C}$ may be due to the obstruction for the flow of $\mathrm{SC}-\mathrm{CO}_{2}$ because of decrease in void space of the packed bed. Figure 3 may be referred. [20-21]

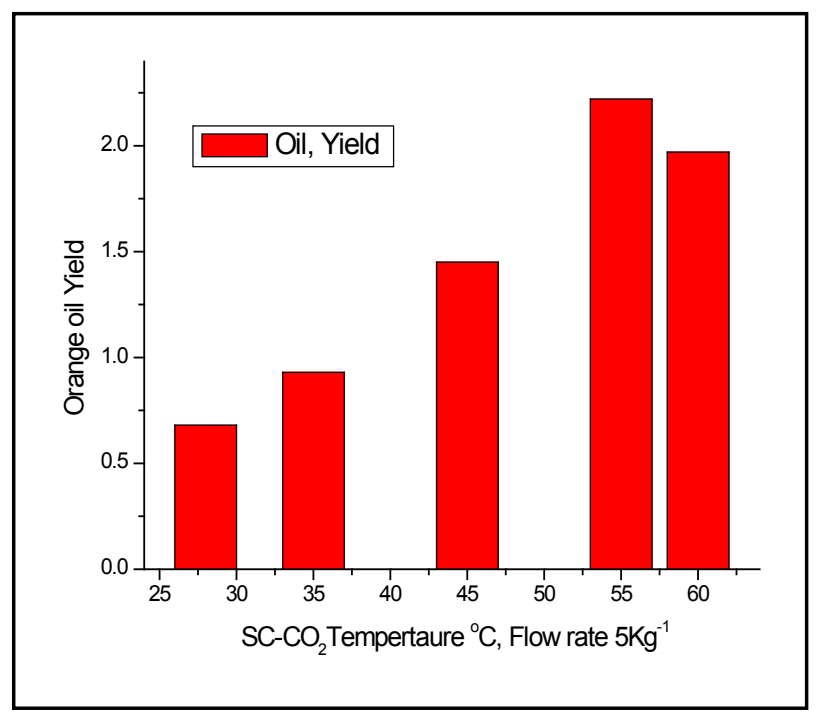

Figure 3. Effect of temperature on extraction of orange peel oil

Table 1. Orange peel oil extraction by $\mathrm{SC}-\mathrm{CO}_{2}$ with temperature variation

\begin{tabular}{|c|c|}
\hline Extraction temperature ${ }^{\circ} \mathrm{C}$ & Yield of oil (wt \% of peels) \\
\hline$* 28$ & 0.68 \\
\hline 35 & 0.93 \\
\hline 45 & 1.45 \\
\hline 55 & 2.22 \\
\hline 60 & 1.97 \\
\hline
\end{tabular}

*subcritical condition operated below critical temperature of $31.1^{\circ} \mathrm{C}$

Extraction pressure:

Flow rate of $\mathrm{CO}_{2}$ :

Batch time: $15 \mathrm{MPa}$

Ground orange peel charged: $\quad 2 \mathrm{~h}$

\subsection{Effect of Temperature on the Extraction of Orange Oil}

In this part of study, (figure 4) temperature was varied between $28^{\circ}$ (subcritical) and $60^{\circ} \mathrm{C}$, the pressure was $15 \mathrm{MPa}$, batch time was 2 hour and flow rate of the SFE was $5 \mathrm{~kg} \mathrm{~h}^{-1}$. It was found that at constant pressure with increase in temperature the yield of orange oil was found to increase till $55^{\circ} \mathrm{C}$. At $60^{\circ} \mathrm{C}$ the extraction of orange oil (table 2) was found to decrease slightly. Major constituents of the oil, d-limonene was found to increase up to $89.28 \%$ at $60^{\circ} \mathrm{C}$. The components $\alpha$-pinene, $\beta$-pinene, terpinolene, $\mathrm{C}_{8}$-aldehyde, linalool and citronellol were found to be less than $1 \%$ while myrecene was less than $3 \%$ in the extracted oil. Thus the temperature of extraction may be kept at $55^{\circ} \mathrm{C}$ at $15 \mathrm{MPa}$ pressure, $2 \mathrm{~h}$ batch time, and $5 \mathrm{~kg} \mathrm{~h}^{-1}$ flow rate of $\mathrm{SC}-\mathrm{CO}_{2} \cdot[20-21]$

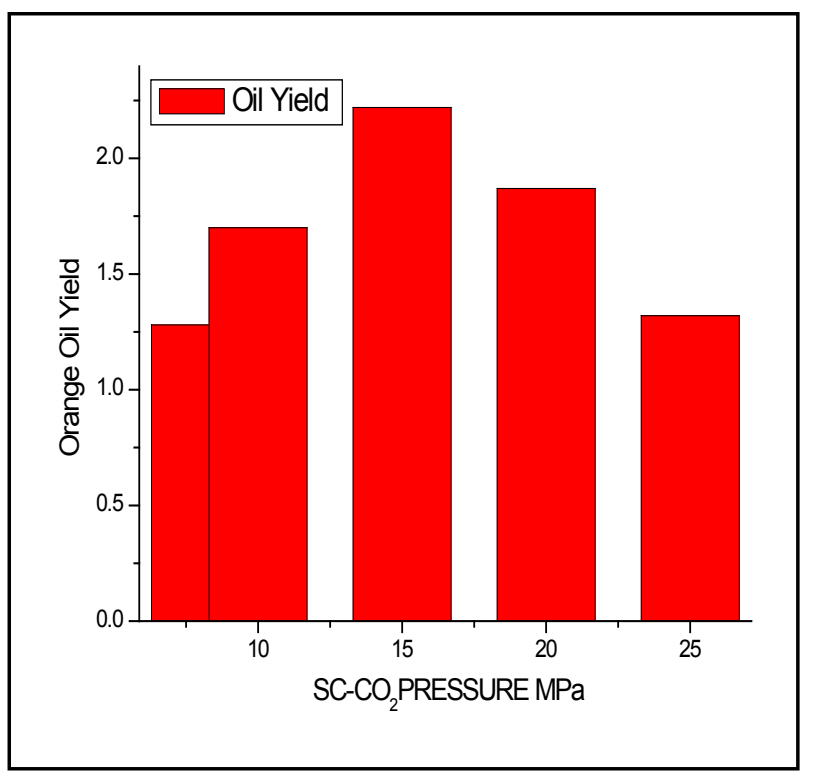

Figure 4. Effect of pressure on extraction of orange peel oil

Table 2. Orange peel oil extraction by $\mathrm{SC}-\mathrm{CO} 2$ with pressure variation

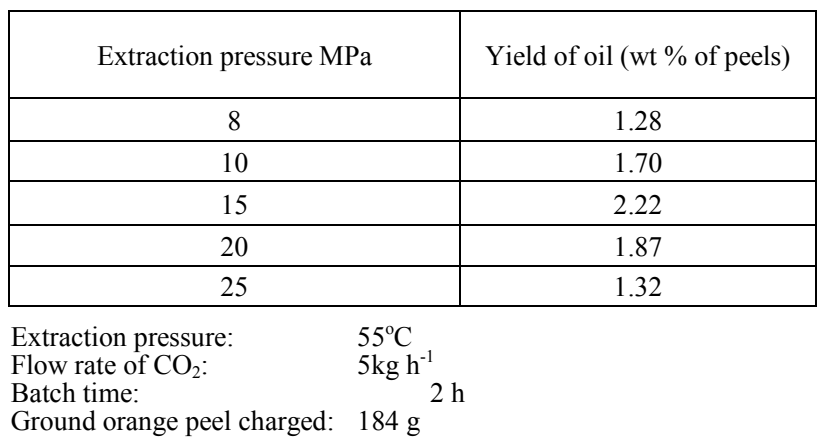

The compositions of the constituents at these conditions were $\alpha$-pinene $(0.14 \%), \quad \beta$-pinene $(0.99 \%)$, myrecene $(2.65 \%)$, d-limonene $(88.68 \%)$, terpinolene $(0.55 \%)$, C8-aldehyde $(0.33 \%)$, citronellol $(0.11 \%)$ and linalool $(0.13 \%)$. The decrease in the extraction of orange oil may be attributed to the fact that above $55^{\circ} \mathrm{C}$ some degradation products start forming, thus reducing the yield.

The composition of the extracted orange oil is presented in table 3 and 4. It was observed that d-limonene was the major constituents (about 90\%) of the oil. The other components 
were $\alpha$-pinene, $\beta$-pinene, myrecene, terpinolene, $\mathrm{C}_{8}$-aldehyde, citronellol and linalool. Out of these except myrecene that is $2.5-3 \%$, the rest of the constituents were less than $1 \%$ each. [20-21]

Table 3. Percent composition of Orange peel oil extracted by $\mathrm{SC}-\mathrm{CO}_{2}$

\begin{tabular}{|c|c|c|c|c|c|c|c|c|}
\hline $\begin{array}{c}\text { Temp } \\
{ }^{\circ} \mathrm{C}\end{array}$ & \multicolumn{9}{|c|}{ \% Composition } \\
\hline & 1 & 2 & 3 & 4 & 5 & 6 & 7 & 8 \\
\hline 28 & 0.08 & 0.58 & 1.97 & 88.25 & 0.58 & 0.16 & 0.45 & 0.24 \\
\hline 35 & 0.10 & 0.76 & 2.30 & 76.72 & 0.58 & 0.27 & 0.16 & 0.12 \\
\hline 45 & 0.10 & 0.75 & 2.09 & 86.72 & 0.16 & 0.38 & 0.10 & 0.46 \\
\hline 50 & 0.14 & 0.99 & 2.65 & 88.68 & 0.55 & 0.33 & 0.11 & 0.75 \\
\hline 55 & 0.12 & 0.79 & 2.27 & 89.28 & 0.54 & 0.14 & 0.41 & 0.13 \\
\hline
\end{tabular}

1) $\alpha$-pinene 2) $\beta$-pinene 3 ) myrecene 4) limonene 5) terpinolene 6) $C_{8}$ aldehyde 7) citronellol 8) linalool

Extraction pressure $15 \mathrm{MPa}$

Percent composition of the orange peel oil at $15 \mathrm{MPa}$ and $55^{\circ} \mathrm{C}$ were $\alpha$-pinene $(0.14 \%), \beta$-pinene $(0.99 \%)$, myrecene $(2.65 \%)$, d-limonene $(88.68 \%)$, terpinolene $(0.55 \%)$, $\mathrm{C}_{8}$-aldehyde $(0.33 \%)$, citronellol $(0.11 \%)$ and linalool (0.75\%).[20-21]

Flow rate of $\mathrm{SC}-\mathrm{CO}_{2}$ was studied varying it in between $5-20 \mathrm{~kg} \mathrm{~h}^{-1}$. But no major impact of the parameter was found on the batch time or yield of the studied process. Since water was found to behaving as an entrainer and hence studying the effect of other polar entariner was kept out of study. That probably would have added to the cost for operating. While increasing the pressure from $8-25 \mathrm{MPa}$, extraction of the orange oil was expected to increase but at pressure of 20 and $25 \mathrm{MPa}$ the yield was found to decrease may be due to compactness of the orange peel bed and resulting in reduced mass transfer. However the yield of the oil was found with good yield at the pressure and temperature of $15 \mathrm{MPa}$ and $40^{\circ} \mathrm{C}$. As the pressure of the $\mathrm{SC}-\mathrm{CO}_{2}$ was increased then the extracted orange oil found to extract carotenoids present in the peels and imparting light yellow color to the extract. The aroma of the oil was as that of fresh peels of the orange.

Table 2. Percent composition of Orange peel oil extracted by $\mathrm{SC}-\mathrm{CO}_{2}$

\begin{tabular}{|c|c|c|c|c|c|c|c|c|}
\hline $\begin{array}{c}\text { Temp } \\
{ }^{\circ} \mathrm{C}\end{array}$ & \multicolumn{7}{|c|}{ \% Composition } \\
\hline & 1 & 2 & 3 & 4 & 5 & 6 & 7 & 8 \\
\hline 28 & 0.08 & 0.58 & 1.97 & 88.25 & 0.58 & 0.16 & 0.45 & 0.24 \\
\hline 35 & 0.10 & 0.76 & 2.30 & 76.72 & 0.58 & 0.27 & 0.16 & 0.12 \\
\hline 45 & 0.10 & 0.75 & 2.09 & 86.72 & 0.16 & 0.38 & 0.10 & 0.46 \\
\hline 50 & 0.14 & 0.99 & 2.65 & 88.68 & 0.55 & 0.33 & 0.11 & 0.75 \\
\hline 55 & 0.12 & 0.79 & 2.27 & 89.28 & 0.54 & 0.14 & 0.41 & 0.13 \\
\hline
\end{tabular}

Extraction temperature $55^{\circ} \mathrm{C}$

Though increase in temperature of $\mathrm{SC}-\mathrm{CO}_{2}$ at constant pressure lowers the density but it was found that the best yield of the oil was obtained at $55^{\circ} \mathrm{C}$ of temperature and may be attributed to the vapor pressure liquid relationship. The progress of extraction of major and minor constituents of the orange oil was comparable to that extracted by conventional hydro distillation. Major disadvantages of conventional technique were long batch time and solubilisation of minor constituents that comprise only of $5 \%$ of the oil. Hence it was a big challenge to retain the minor constituents of the oil that adds the value to the oil. $\mathrm{SC}-\mathrm{CO}_{2}$ may be advantageous due to eco friendly process.

\section{Conclusions}

The optimum conditions for the volatile oil extraction of orange peels using $\mathrm{SC}-\mathrm{CO}_{2}$ were $55^{\circ} \mathrm{C}, 15 \mathrm{MPa}$ pressure, $5 \mathrm{~kg}$ $\mathrm{h}^{-1}$ of flow rate and 2 hour batch time. The yield of the oil was $2.22 \mathrm{wt} \%$. This was certainly highest yield obtained by $\mathrm{SC}-\mathrm{CO}_{2}$ against the values reported in the extensive literature search. Quality of oil was absolutely fragrant and resembling as that of fresh orange peel. The color of the oil was light pale yellow color.

Various treatments were given to orange peels. The best results were obtained when sun dried ground peels stored in cooling chambers at $0^{\circ} \mathrm{C}$ were extracted by hydro distillation. The yield of the oil varied from $3.42 \mathrm{wt} \%-3.99 \mathrm{wt} \%$. The $\mathrm{pH}$ of water was found to be acidic. The oil obtained by hydro distillation was colorless and with more terpenic note. The oil extracted by the $\mathrm{SC}-\mathrm{CO}_{2}$ was with very less terpenic.

\section{ACKNOWLEDGEMENTS}

All the Technical assistant staff especially Mr. U.R. Paralkar of Institute of Chemical Technology, Mumbai, deserves special thanks for his efforts in analyzing the oil by $\mathrm{GC}$ and in time repairing of the supercritical carbon dioxide pilot plant.

\section{Supporting Information}

Oranges as whole are abundantly used by the food industries in India for recovering the juices. As a result huge amount of peels accumulates over the periods of processing. This could be great concern for the environment due to their biodegradability and hence our efforts were to develop strategically extraction process using SFE technology which itself is a green technology for recovering the Orange oil which has great demands in the international market for the usages in the field of perfume, flavors, pharmaceuticals, beverages, baking industries. It was found to be a successful project and may be exploited on the large scales.

\section{REFERENCES}


[1] Mira B., Blasco M., Subirats S., Berna A., 1996, Supercritical $\mathrm{CO}_{2}$ extraction of essential oils from orange peel, J. supercritical fluids, 9, 238-246

[2] Braddock R. J., 1995, By-products of citrus fruits. Food Tech., 49, 74, 76-77.

[3] Braddock R. J. 1999, Hand Book of Citrus By-Products and Processing Technology. New York: John Wiley \& Sons, Inc.

[4] British Pharmaceutical Codex 1949, 163

[5] Carolina Simó et al. 2001 Analysis of Antioxidants from Orange Juice Obtained by Counter current Supercritical Fluid Extraction, Using Micellar Electro kinetic Chromatography and Reverse-Phase Liquid Chromatography, J. Agric. Food Chem., 50(23):6648-6652 DOI: 10.1021/jf025590u Publication Date (Web): October 2, 2002

[6] Crandall P. G., Kesterson, J. W., Dennis, S., 1983, Storage stability of carotenoids in orange peel oil, J. food Sci. 48. 924-27

[7] Dugo, G., 1994, the composition of the volatile fraction of the Italian citrus essential oils. Perf. \& Flav, 19, 2951

[8] Della Porta G., 1996, Bigarade Peel Oil Fractionation by Supercritical Carbon Dioxide Desorption, J. Agric. Food Chem., 44 (4), 1100-1104

[9] Giannuzzo A. N., Boggetti H.. J., Nazareno M. A., Mishima H. T., 2003, Supercritical fluid extraction of naringin from the peel of Citrus paradisi. Phyto. Anal., 14: 221-223.

[10] Gonzalom, A. N., Jos M..D. Valle J. C., de la Fuente. 2010, Solubilities in Supercritical Carbon Dioxide of (2E, 6E)-3, 7, 11-Trimethyldodeca-2, 6, 10-trien-1-ol (Farnesol) and (2S)-5, 7-Dihydroxy-2-(4-hydroxyphenyl) chroman-4-one (Naringenin), J. Chem. Eng. Data, 55(9):3863-3868

[11] Masaki S., Motonobu, G., Tsutomu, H., 1996, Supercritical Fluid Extraction on Semi batch mode for the Removal of Terpene in Citrus Oil, Ind. \& Eng. Chem. Res. 35(6):1906-1911
[12] Moshonas, M. G, Shaw P. E., 1974, Quantitative and qualitative analysis of tangerine peel oil, J. Agric. Food Chem., 22, 282-284

[13] Ohta H., 1992, Glass capillary gas chromatographic identification of volatile components recovered from orange essence by continuous liquid extraction, J. Chromatogr. 268, 336-340

[14] Poiana M., Fresa R., Mincione B., 1999, Supercritical carbon dioxide extraction of bergamot peels. Extraction kinetics of oil and its components, Flav. frag. J. 14, 358-366.

[15] Roselius W. et al., (1982) Method of extracting coffee oil containing aroma constituents from roasted coffee under supercritical conditions, US Pat 4328255, May 4

[16] Sattar, A., Mahmud. S. (1986) Citrus Oil, Composition of Monoterpenes of the peel oil of Orange, Kinnow and Lemon, Pak. J. Sci. Ind. Res., 29, 196-198.

[17] Sawamura M., 1989, Comparison of peel oil components of yuzu (Citrus junos Tanaka) extracted by supercritical carbon dioxide and those of traditional ones, Nippon Shokuhin Kogyo Gakkaishi, 36, 34-38

[18] Shin, D. H.,1992, Supercritical carbon dioxide extraction of terpene hydrocarbons from constructed citrus peel oil, Nippon Shokuhin Kogyo Gakkaishi, 39, 377-389

[19] Sugisawa H., 1989, Volatile constituents in the peel oil of Sudachi (citrus sudachi), Agric. Bio. Chem., 53(6), 1721-23

[20] Berna, A., Tarrega A.., Biasco, M., Subirats, S., 2000, Supercritical $\mathrm{CO}_{2}$ extraction of essential oil from orange peel; effect of the height of the bed, J. Supercritical Fluid, 18(3), 227-237

[21] Wilson III C. W., Shaw P. E. 1977, Separation of pigments flavonoids, flavor fractions from citrus oil by gel permeation chromatography, J. Agric. Food Chem., 25(2), 221-224 